\title{
Syntheses, Crystal Structures, and Spectral Properties of Two Coordination Compounds Based on 1,2-Bis(benzimidazolyl)benzene
}

\author{
Fa-Yan Meng, Bing-Li Jiang, Cui-Wu Lin," Li Wang, and Xiao-He Tan
}

\author{
College of Chemistry and Chemical Engineering, Guangxi University, Guangxi 530004, P. R. China \\ ${ }^{*}$ E-mail: cuiwulin@yahoo.com.cn \\ Received October 2, 2010, Accepted December 7, 2010
}

\begin{abstract}
Two new benzimidazolyl-containing complexes have been synthesized by reactions of $\mathrm{Cu}^{\mathrm{II}}$ salts and 1,2-bis(benzimidazolyl)benzene $\left(\mathrm{H}_{2} \mathrm{bbbz}\right)$ with two different dicarboxylate ligands. When phthalate acid $\left(\mathrm{H}_{2} \mathrm{pt}\right)$ was employed as secondary ligand, a 0D molecular complex $\mathrm{Cu}\left(\mathrm{H}_{2} \mathrm{bbbz}\right)(\mathrm{pt}) \cdot\left(\mathrm{H}_{2} \mathrm{pt}\right)(\mathbf{1})$ was furnished and when the secondary ligand was instead by a linear bridging ligand of terephthalic acid $\left(\mathrm{H}_{2} \mathrm{tp}\right)$ a $1 \mathrm{D}$ zipper-like coordination polymer $\left[\mathrm{Cu}\left(\mathrm{H}_{2} \mathrm{bbbz}\right)\right.$ $\left.(\mathrm{tp}) \cdot 2\left(\mathrm{C}_{2} \mathrm{H}_{5} \mathrm{OH}\right) \cdot \mathrm{H}_{2} \mathrm{O}\right]_{\mathrm{n}}(2)$ was obtained, suggesting the structure-direction effect of the secondary dicarbxylate ligand. The preliminary investigation on the spectral properties of the complexes was also presented.
\end{abstract}

Key Words : Copper (II), 1,2-Bis(benzimidazolyl)benzene, Dicarboxylate, Crystal structures, Spectral properties

\section{Introduction}

The rational design and synthesis of novel metal-organic coordination complexes have attracted great interests for decades, owing to their structural diversities ${ }^{1}$ and potential applications in molecular magnetism, ${ }^{2}$ ion exchange, ${ }^{3}$ gas storage and sequestration, ${ }^{4}$ catalysis, ${ }^{5}$ non-linear optics, ${ }^{6}$ luminescence ${ }^{7}$ and porosity or zeolitic behaviors. ${ }^{8}$ So far, a number of investigations focused on the theoretical analysis and practical manipulation about the controllable self-assembly of coordination complexes have been studied. ${ }^{9}$ The control of dimensionality of the complexes, however, is still an arduous challenge to chemists, because the final structures are always influenced by various factors. ${ }^{10}$ It is well known that the coordination mode of ligand is to a certain extent the key factor that can determine the final structural dimensionalities of the compounds. Change of the organic ligand, such as the length, flexibility and conformational preference can result in a remarkable class of complexes bearing diverse architectures and functions. ${ }^{11}$

Imidazole and benzimidazole ligands, widely used in research of novel coordination compounds especially the zeolitic imidazolate frameworks (ZIFs), have been proved to be good candidates for multifunctional ligands. ${ }^{12}$ For example, 2,2'-bibenzimidazole $\left(\mathrm{H}_{2} \text { bbim }\right)^{13}$ and its analogues,${ }^{14}$ can serve as neutral bidentate, tridentate or tetradentate ligands to assemble multidimensional coordination complexes from $0 \mathrm{D}$ molecules to $3 \mathrm{D}$ polymers. The asymmetric ligands, 2-(3-pyridyl)benzimidazole (3-PyBim) and 2-(4-pyridyl)benzimidazole (4-PyBim), can coordinate with different metal to provide low dimensional building units which are able to propagate into $1 \mathrm{D}, 2 \mathrm{D}$, or $3 \mathrm{D}$ structures via hydrogen bonds and other intermolecular weak interactions. ${ }^{15}$

On the other hand, design and construction of coordination complexes based on polycarboxylate anions and metal ions have aroused enormous attentions. ${ }^{16}$ Many researches have been intensively focused on construction of coordination complexes by exploiting saturated aliphatic dicarboxylate ligands, which are of special interests due to their conformational versatilities, including discrete zero-dimensional (0D) complexes, ${ }^{1(d)} 1 \mathrm{D}$ polymeric chains, ${ }^{17}$ 2D layers ${ }^{18}$ and $3 \mathrm{D}$ frameworks. ${ }^{19}$ For the aromatic carboxylate ligands, such as 1,4-benzenedicarboxylic $\left(\mathrm{H}_{2}\right.$ bdc) acid and 1,2,4,5-benzenetetracarboxylic acid $\left(\mathrm{H}_{4}\right.$ btec $)$ are extensively exploited in the construction of architectures through their self-assembly, forming coordination polymer chains, layers or networks. ${ }^{20}$

Taking this into consideration, we selected two dicarboxylic acids as secondary ligands to tune the dimensionality of the complexes based on benzimidazole-like ligands. Although many metal-polycarboxylate complexes based on benzimidazole-like ligands have been obtained and reported, the metalorganic compounds derived from 1,2-bis(benzimidazolyl)benzene $\left(\mathrm{H}_{2} \mathrm{bbbz}\right),{ }^{21}$ however, have not been investigated before.

In this work, two metal-organic coordination complexes based on $\mathrm{H}_{2}$ bbbz have been prepared by reaction of $\mathrm{Cu}(\mathrm{II}) \mathrm{salts}, \mathrm{H}_{2} \mathrm{bbbz}$ with phthalate acid $\left(\mathrm{H}_{2} \mathrm{pt}\right)$ and terephthalic acid $\left(\mathrm{H}_{2} \mathrm{tp}\right)$. Compound $1 \mathrm{Cu}\left(\mathrm{H}_{2} \mathrm{bbbz}\right)(\mathrm{pt}) \cdot\left(\mathrm{H}_{2} \mathrm{pt}\right)$ is a mononuclear compound and compound $\left.2 \mathrm{Cu}\left(\mathrm{H}_{2} \mathrm{bbbz}\right)(\mathrm{tp}) \cdot 2\left(\mathrm{C}_{2} \mathrm{H}_{5} \mathrm{OH}\right) \cdot \mathrm{H}_{2} \mathrm{O}\right]_{\mathrm{n}}$ features a zipper chain in the structure.

\section{Experimental}

General. All chemicals and solvents used were analytically pure and without further purification. Elemental analysis for $\mathrm{C}, \mathrm{H}$, and $\mathrm{N}$ was carried out on a Perkin-Elmer 2400 II elemental analyzer. The UV absorption spectra was recorded on a model UV-2501 spectrophotometer (Shimazu, Janpan). Fluorescence measurements were performed on a Model RF-5301 spectrofluorimeter (Shimazu, Japan).

\section{Synthesis.}

Synthesis $\mathbf{C u}\left(\mathbf{H}_{2} \mathbf{b b b z}\right)(\mathbf{p t}) \cdot\left(\mathbf{H}_{2} \mathbf{p t}\right)$ (1): To an aqueous solution $(5 \mathrm{~mL})$ of $\mathrm{Cu}\left(\mathrm{NO}_{3}\right)_{2} \cdot 1.5 \mathrm{H}_{2} \mathrm{O}(45.67 \mathrm{mg}, 0.2 \mathrm{mmol})$ was added an ethanol solution $(10 \mathrm{~mL})$ of $\mathrm{H}_{2} \mathrm{bbbz}(38.24 \mathrm{mg}, 0.1 \mathrm{mmol})$, and then added $\mathrm{H}_{2} \mathrm{pt}(16.60 \mathrm{mg}, 0.1 \mathrm{mmol})$ to the mixture. After stirring for $20 \mathrm{~min}$, the mixture was left for evaporating at room temperature for several days to obtain purple block crystal (yield ca. $20 \%$ based on $\mathrm{Cu}^{\text {II }}$ ). Anal. Calcd for $\mathrm{C}_{56} \mathrm{H}_{38} \mathrm{CuN}_{8} \mathrm{O}_{8}(\%)$ : 
Table 1. Crystallographic data for complex 1 and $\mathbf{2}$

\begin{tabular}{|c|c|c|}
\hline & 1 & 2 \\
\hline Formula & C56 H38 Cu N8 O8 & $\mathrm{C} 62 \mathrm{H} 58 \mathrm{Cu} 2 \mathrm{~N} 8 \mathrm{O} 13$ \\
\hline$M_{\mathrm{r}}$ & 1014.47 & 1250.24 \\
\hline Cryst. size, $\mathrm{mm}^{3}$ & $0.45 \times 0.38 \times 0.34$ & $0.47 \times 0.43 \times 0.15$ \\
\hline Crystal system & Triclinic & Monoclinic \\
\hline Space group & $P-1$ & $C 2 / c$ \\
\hline$a, \AA$ & $11.493(5)$ & $24.358(2)$ \\
\hline$b, \AA$ & $15.851(7)$ & $18.3295(1)$ \\
\hline$c, \AA$ & $27.637(15)$ & $16.8531(2)$ \\
\hline$\alpha, \operatorname{deg}$ & $103.667(9)$ & 90 \\
\hline$\beta, \operatorname{deg}$ & $91.845(9)$ & 129.82 \\
\hline$\gamma, \operatorname{deg}$ & $107.709(6)$ & 90 \\
\hline$V, \AA^{3}$ & $4631(4)$ & $5778.7(6)$ \\
\hline$Z$ & 4 & 4 \\
\hline$D_{\text {calcd }}, \mathrm{g} \mathrm{cm}^{-3}$ & 1.452 & 1.437 \\
\hline$\mu($ Mo K $\alpha), \mathrm{mm}^{-1}$ & 0.541 & 0.809 \\
\hline$F(000)$, e & 2084 & 2592 \\
\hline$h k l$ range & $\begin{array}{c}-13 \leq h \leq 13, \\
17 \leq \mathrm{k} \leq 18,-32 \leq 1 \leq 19\end{array}$ & $\begin{array}{c}-29 \leq \mathrm{h} \leq 28, \\
-21 \leq \mathrm{k} \leq 21,-20 \leq 1 \leq 20\end{array}$ \\
\hline Refl. measured & 24803 & 16597 \\
\hline Refl. unique & 16136 & 5134 \\
\hline$R_{\text {int }}$ & 0.0391 & 0.0486 \\
\hline Param. refined & $\begin{array}{c}\text { Full-matrix } \\
\text { least-squares on } \mathrm{F}^{\wedge} 2\end{array}$ & $\begin{array}{c}\text { Full-matrix } \\
\text { least-squares on } \mathrm{F}^{\wedge} 2\end{array}$ \\
\hline $\begin{array}{l}R(F) / w R\left(F^{2}\right)^{a} \\
\text { (all reflexions) }\end{array}$ & $0.1213 / 0.2126$ & $0.0674 / 0.1140$ \\
\hline $\mathrm{GoF}\left(F^{2}\right)^{a}$ & 1.101 & 1.028 \\
\hline$\stackrel{\Delta \rho_{\text {fin }}(\max / \min )}{\text { e } \AA^{-3}}$ & $0.872 /-0.361$ & $0.477 /-0.362$ \\
\hline
\end{tabular}

${ }^{a}$ The structure was solved by direct methods and refined by full-matrix least-squares fitting on $F^{2}$ by SHELXL-97.

C, 66.30; H, 3.78; N, 11.05. Found: C, 66.22; H, 3.85; N, 11.12 . IR data for $1\left(\mathrm{KBr}, \mathrm{cm}^{-1}\right)$ : $3670(\mathrm{~s}), 3070(\mathrm{~s}), 1445(\mathrm{~m}), 1359(\mathrm{~s})$, 1322(v), 1287(m), 986(s), 791(s), 745(s).

Synthesis $\left[\mathbf{C u}\left(\mathrm{H}_{2} \mathbf{b b b z}\right)(\mathrm{tp}) \cdot \mathbf{2}\left(\mathrm{C}_{2} \mathrm{H}_{5} \mathrm{OH}\right) \cdot \mathrm{H}_{2} \mathrm{O}\right] \mathbf{n}(\mathbf{2})$ : To an aqueous solution $(5 \mathrm{~mL})$ of $\mathrm{Cu}\left(\mathrm{NO}_{3}\right)_{2} \cdot 1.5 \mathrm{H}_{2} \mathrm{O}(45.67 \mathrm{mg}, 0.2$ mmol) was added an ethanol solution $(10 \mathrm{~mL})$ of $\mathrm{H}_{2} \mathrm{bbbz}(38.24$ $\mathrm{mg}, 0.1 \mathrm{mmol})$, and then added $\mathrm{H}_{2} \mathrm{pt}(16.60 \mathrm{mg}$, mmol) to the mixture. After stirring for $20 \mathrm{~min}$, the mixture was left for evaporating at room temperature to obtain purple hexagon crystal after ten days. (yield $c a$. $10 \%$ based on $\mathrm{Cu}^{\mathrm{II}}$ ). Anal. Calcd for $\mathrm{C}_{62} \mathrm{H}_{58} \mathrm{Cu}_{2} \mathrm{~N}_{8} \mathrm{O}_{13}$ (\%): C, 59.60; H, 4.68; N, 8.96. Found: $\mathrm{C}$, $59.67 ; \mathrm{H}, 4.60 ; \mathrm{N}, 9.01$. IR data for $2\left(\mathrm{KBr}, \mathrm{cm}^{-1}\right): 3682(\mathrm{~s}), 3073$ (m), 1580(s), 1503(v), 1446(s), 1379(s), 988(m), 837(m), 744(s).

X-ray Crystallography. The X-ray diffraction intensity data for the crystals was collected using Mo $\mathrm{K} \alpha$ radiation $(\lambda=$ $0.71073 \AA$ ) on a Brucker SMART CCD diffractometer in the $h$ scan mode at 296(2) K. Structure solution and refinement were carried out using the programmes SHELXS 97 and SHELXL97. ${ }^{22}$ The hydrogen atoms associated with carbon and nitrogen atoms were generated geometrically, and the hydrogen atoms attached to $\mathrm{H}_{2} \mathrm{O}$ were located from difference Fourier syntheses. The crystal data and structure refinement details for complex $\mathbf{1}$ and $\mathbf{2}$ are given in Table 1. Selected bond lengths
Table 2. Selected bond lengths $(\AA)$ and angles $\left({ }^{\circ}\right)$ for $\mathbf{1}$ and $\mathbf{2}$

\begin{tabular}{|c|c|c|c|}
\hline \multicolumn{4}{|l|}{ Complex 1} \\
\hline $\mathrm{Cu} 1-\mathrm{O} 8$ & $2.354(4)$ & $\mathrm{Cu} 2-\mathrm{N} 10$ & $1.985(4)$ \\
\hline Cu1-N1 & $1.982(4)$ & $\mathrm{Cu} 2-\mathrm{N} 11$ & $1.991(4)$ \\
\hline Cu1-N4 & $2.009(4)$ & $\mathrm{Cu} 2-\mathrm{N} 14$ & $1.983(4)$ \\
\hline Cu1-N5 & $1.990(4)$ & $\mathrm{Cu} 2-\mathrm{N} 15$ & $1.985(4)$ \\
\hline Cu1-N8 & $2.001(4)$ & $\mathrm{Cu} 2-\mathrm{O} 13$ & $2.426(4)$ \\
\hline O8-Cu1-N1 & $90.64(13)$ & O8-Cu1-N4 & $91.70(13)$ \\
\hline O8-Cu1-N5 & $101.93(13)$ & O8-Cu1-N8 & $97.08(13)$ \\
\hline N1-Cu1-N4 & $91.73(15)$ & N1-Cu1-N5 & $167.21(14)$ \\
\hline N1-Cu1-N8 & $91.70(15)$ & N4-Cu1-N5 & $90.28(15)$ \\
\hline N4-Cu1-N8 & $170.53(14)$ & N5-Cu1-N8 & $84.47(15)$ \\
\hline N10-Cu2-N11 & $90.54(16)$ & $\mathrm{N} 10-\mathrm{Cu} 2-\mathrm{N} 14$ & $171.11(14)$ \\
\hline N10-Cu2-N15 & $91.63(16)$ & N11-Cu2-N14 & $84.96(16)$ \\
\hline N11-Cu2-N15 & $168.70(19)$ & N14-Cu2-N15 & $91.34(17)$ \\
\hline O13-Cu2-N14 & $97.19(13)$ & $\mathrm{O} 13-\mathrm{Cu} 2-\mathrm{N} 15$ & $89.73(16)$ \\
\hline $\mathrm{O} 13-\mathrm{Cu} 2-\mathrm{N} 10$ & $91.20(13)$ & $\mathrm{O} 13-\mathrm{Cu} 2-\mathrm{N} 11$ & $101.32(16)$ \\
\hline \multicolumn{4}{|l|}{ Complex 2} \\
\hline $\mathrm{Cu} 1-\mathrm{O} 6$ & $2.399(3)$ & $\mathrm{Cu} 1-\mathrm{O} 7$ & $1.940(2)$ \\
\hline $\mathrm{Cu} 1-\mathrm{O} 5$ & $2.001(2)$ & Cu1-N3 & $1.967(2)$ \\
\hline Cu1-N1 & $1.950(3)$ & & \\
\hline O5-Cu1-O6 & $58.53(9)$ & O5-Cu1-O7 & 88.98(9) \\
\hline O5-Cu1-N1 & $92.08(10)$ & O5-Cu1-N3 & $165.94(11)$ \\
\hline O5-Cu1-C28 & $29.24(10)$ & O6-Cu1-O7 & $90.94(10)$ \\
\hline O6-Cu1-N1 & $98.03(10)$ & O6-Cu1-N3 & $107.41(10)$ \\
\hline O6-Cu1-C28 & $29.30(9)$ & O7-Cu1-N1 & $170.07(11)$ \\
\hline O7-Cu1-N3 & $91.52(10)$ & O7-Cu1-C28 & $89.42(10)$ \\
\hline N1-Cu1-N3 & $89.85(10)$ & N1-Cu1-C28 & $96.31(11)$ \\
\hline N3-Cu1-C28 & $136.71(12)$ & & \\
\hline
\end{tabular}

$(\AA)$ and angles $\left({ }^{\circ}\right)$ are listed in Table 2. Crystallographic data have been deposited with the Cambridge Crystallographic Data Centre as supplementary publication No.CCDC-777823 for $\mathbf{1}$, CCDC-7777824 for 2 . These data can be obtained free of charge from the Cambridge Crystallographic Data Centre via www. ccdc.cam.ac.uk/data-request/cif.

\section{Results and Discussion}

Single-crystal X-ray diffraction measurement (Table 1) reveals that compound 1 crystallizes in the triclinic space group $P-1$. In the asymmetry unit, there are two crystallographic-independent mononuclear $\mathrm{Cu}\left(\mathrm{H}_{2} \mathrm{bbbz}\right)_{2}(\mathrm{pt})$ molecules and two $\mathrm{H}_{2} \mathrm{pt}$ guest molecules (Fig. 1). In each molecule, the $\mathrm{Cu}$ (II) ion is fivecoordinated by four nitrogen atoms from two protonated $\mathrm{H}_{2} \mathrm{bbbz}$ ligands and one oxygen atom from $p t$ molecule. The $\tau$ value of 0.055 ( $\tau=0$ for an ideal square-pyramid and $\tau=1$ for an ideal trigonal bipyramid) indicates the geometry is a slightly distorted square pyramid with the axial site occupied by $\mathrm{O}(8) .^{23}$ The $\mathrm{H}_{2}$ bbbz in 1 acts as a bidentate ligand via its benzimidazole nitrogen atoms. The $\mathrm{Cu}-\mathrm{N}$ and $\mathrm{Cu}-\mathrm{O}$ bonds lengths in the two mononuclear molecules are close and the average $\mathrm{Cu}-\mathrm{N}$ bonds lengths are comparable with the corresponding ones of reported $\mathrm{CuN} 4 \mathrm{O}$ coordinated compound while the $\mathrm{Cu}-\mathrm{O}$ bonds lengths are slightly longer. ${ }^{24}$ The two benzimidazolyl rings of the $\mathrm{H}_{2} \mathrm{bbbz}$ in the complex form a dihedral angle of $73.8^{\circ}$, larger than the angle in the ligand $\left(67.2^{\circ}\right) .^{21(b)}$ 


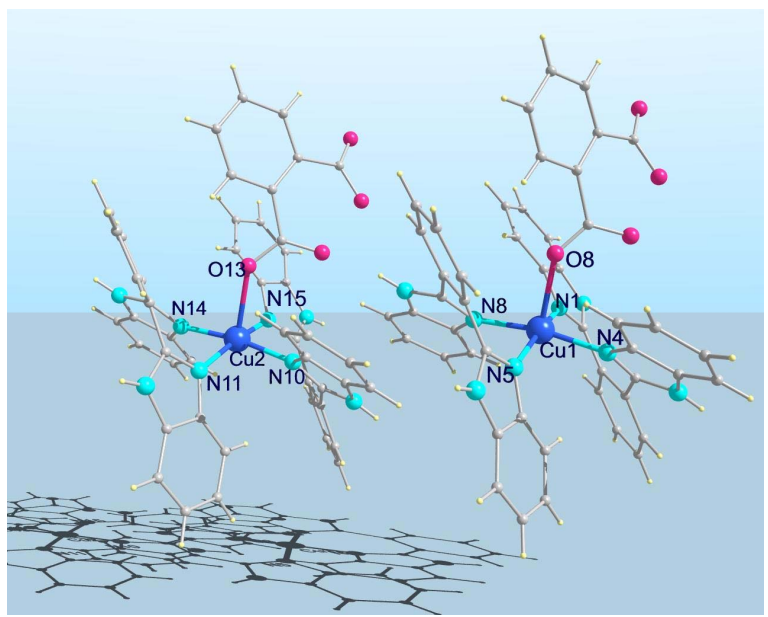

Figure 1. The metal coordination environment in $\mathbf{1}$. The uncoordinated molecules were omitted for clarity.

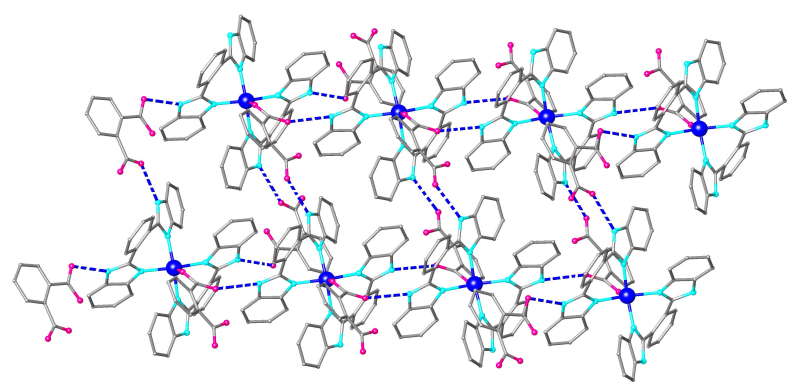

Figure 2. 1D double-strand chains formed by hydrogen bonds in complex 1.

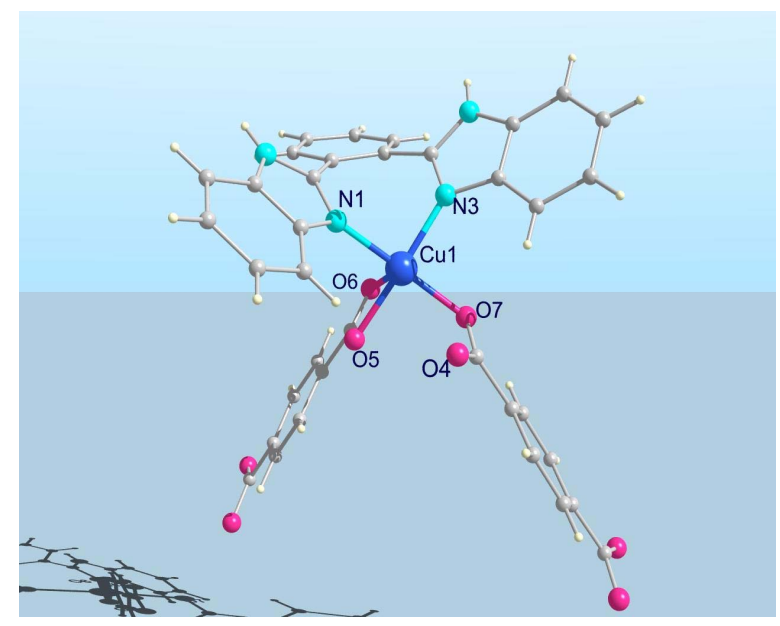

Figure 3. The metal coordination environment in $\mathbf{2}$. The uncoordinated molecules were omitted for clarity.

The molecules are connected through the $\mathrm{N}-\mathrm{H} \cdots \mathrm{O}$ hydrogen bonds (Table S1) to form 1D supramolecular double-stranded chains (Fig. 2), the chains are further connected through $\mathrm{C}-\mathrm{H} \cdots \mathrm{O}$ interaction (Table S2) to construct a three-dimensional architectures (Fig. S1). The uncoordinated $\mathrm{H}_{2}$ pt ligands fill in the remaining unoccupied space, making additional contribution to the stabilization of the structure. (a)

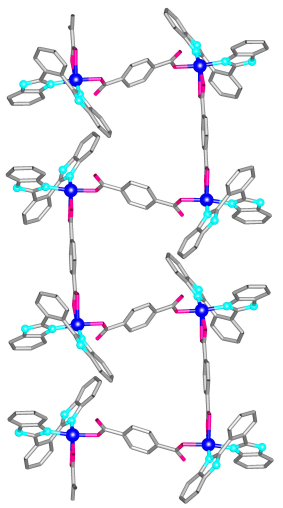

(b)

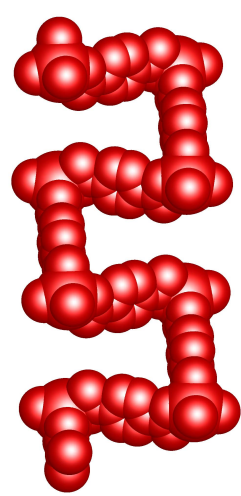

Figure 4. (a) The 1D chains are linked by the monodentated and bidentate bridging tp ligands. (b) The space filling model of $\mathbf{2}$ showing zipperlike chain, some atoms were omitted.

Differently, when the secondary ligand $\mathrm{H}_{2}$ tp was used, the similar reaction gives a zipper-like coordination polymer of 2 . As shown in Fig. 3. The crystal of $\mathbf{2}$ conforms to the space group $C 2 / c$. Each independent crystallographic unit contains a $\mathrm{Cu}^{\mathrm{II}}$ atom, a tp molecule, a $\mathrm{H}_{2}$ bbbz ligand, two ethanol molecules and a lattice water molecule. Each $\mathrm{Cu}^{\mathrm{II}}$ atom is primarily coordinated by two nitrogen atoms from a chelate $\mathrm{H}_{2}$ bbbz and three oxygen atoms from one bidentate tp and one monodentate tp ligand to furnish a distorted square pyramidal coordination geometry, of which the $\tau$ value is 0.069 , slightly larger than 1 , which may be attributed to the small bite angle of chelating carboxylate. $^{23}$ The analogous bond lengths in each benzimidazole ring are not significantly different. The dihedral angle between the two benzimidazolyl rings is $111.9^{\circ}$. The dihedral angles between benzimidazole rings with the benzene ring are $132.3^{\circ}$ and $41.8^{\circ}$, respectively. The $\mathrm{Cu}-\mathrm{N}$ bond lengths fall into the range $1.950(3)$ to $1.967(2) \AA$, comparable with $\mathrm{Cu}-\mathrm{N}$ bond lengths of reported complex, ${ }^{25}$ while the $\mathrm{Cu}-\mathrm{O}$ bond lenghts (1.940(2) to 2.399(3) $\AA$ ) are longer than the corresponding ones. The $\mathrm{tp}^{2-}$ anion adopts chelating-bidentate and monodentate modes to link $\mathrm{Cu}$ (II) cations to form one-dimensional zipperlike chain running along the $a$-axis, as depicted in Fig. 4 , the $\mathrm{H}_{2}$ bbbz phenyl rings at each side of the zipper-like chain are arranged in an off-set fashion; adjacent chains are connected through $\mathrm{N}-\mathrm{H} \cdots \mathrm{O}$ and $\mathrm{O}-\mathrm{H} \cdots \mathrm{O}$ hydrogen bonds $(\mathrm{N}(2)-\mathrm{H}(2 \mathrm{~A}) \cdots$ $\mathrm{O}(3)$ 2.710, $\mathrm{O}(1)-\mathrm{H}(1 \mathrm{~A}) \cdots \mathrm{O}(6) 2.721$ and $\mathrm{O}(3)-\mathrm{H}(3 \mathrm{WA}) \cdots \mathrm{O}(7)$ $2.856 \AA$ ) (Table S3), each pair of polymeric chains are linked together through face to face $\pi-\pi$ stacking interactions between the benzimidazole ligands ( $3.535 \AA)$, indicating a strong aromatic $\pi-\pi$ stacking interaction (Fig. S2). ${ }^{26}$

The UV-vis spectra of free $\mathrm{H}_{2} \mathrm{bbbz}$ and the complexes 1 and $\mathbf{2}$ are studied in the ethanol solution at room temperature (Fig. S3). The ligand $\mathrm{H}_{2}$ bbbz and complex 1 display similar absorption bands ranging from 220 to $320 \mathrm{~nm}$, indicating the intraligand $\pi \rightarrow \pi^{*}$ electronic transitions, originating from the imidazole groups. ${ }^{27}$ The maximum absorption of complex 2 has a strong band at $c a$. $220 \mathrm{~nm}$, which can be assigned to metal-toligand charge transfer (MLCT).

In ethanol solution, the emission spectra of free ligand and complexes $\mathbf{1}$ and $\mathbf{2}$ were measured at room temperature (Fig. 5). The ligand $\mathrm{H}_{2}$ bbbz displays a strong emission band at $403 \mathrm{~nm}$ 


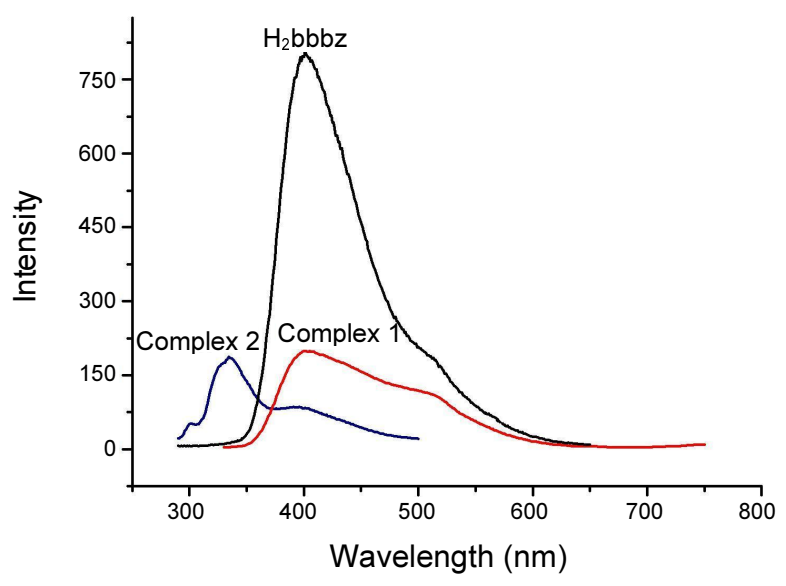

Figure 5. Fluorescence spectra of the $\mathrm{H}_{2}$ bbbz ligand, complex 1 and 2 in the ethanol solution.

upon excitation at $282 \mathrm{~nm}$ and the maximum emission peak is $120 \mathrm{~nm}$ red-shifted compared to the related absorption band, similar to other compounds containing benzimidazole group, ${ }^{27,28}$ which could be attributed to the $\pi \rightarrow \pi^{*}$ transition. The emission band of complex 1 is similar to that of the ligand (upon excitation at $275 \mathrm{~nm}$ ), this phenomenon may be ascribed to the typical intraligand charge transfer (ILCT) which has also been observed in a series of imidazole-metal analogues. ${ }^{29}$ The compound 2 displays a maximum emission at $334 \mathrm{~nm}$ upon excitation at $275 \mathrm{~nm}$. Compared to the free $\mathrm{H}_{2} \mathrm{bbbz}$ ligand, compound 2 has a blue shift of $c a .70 \mathrm{~nm}$ which can be attributed to metalto-ligand charge transfer (MLCT) ${ }^{30}$ while the shoulder peaks at $400 \mathrm{~nm}$ may be attributable to intraligand charge transfer (ILCT). ${ }^{31}$ Significant difference of emission between $\mathbf{1}$ and $\mathbf{2}$ is probably due to the differences of anions and coordination environment around central metal ions, because photoluminescence behavior is closely associated with the local environments around metal ions. ${ }^{32}$

\section{Conclusion}

In summary, taking advantage of dicarboxylate organic molecules as secondary ligands, we have prepared and characterized two new metal-organic coordination complexes $\left[\mathrm{Cu}\left(\mathrm{H}_{2} \mathrm{bbbz}\right)\right.$ $\left.(\mathrm{pt})] \cdot\left(\mathrm{H}_{2} \mathrm{pt}\right)\right]$ and $\left[\mathrm{Cu}\left(\mathrm{H}_{2} \mathrm{bbbz}\right)(\mathrm{tp}) \cdot 2\left(\mathrm{C}_{2} \mathrm{H}_{5} \mathrm{OH}\right) \cdot \mathrm{H}_{2} \mathrm{O}\right]_{\mathrm{n}}$, which contain discrete $0 \mathrm{D}$ molecule and infinite $1 \mathrm{D}$ zipper chain, respectively. The crystal structures show that the secondary ligands have an important influence on the resulting structures. The new compounds exhibit different luminescence in the ethanol solution which may be attributed to the different coordination effect.

Acknowledgments. This work was supported by a grant for the National Natural Science Foundation of China (20962002, 20662001) and National Undergraduates Innovating Experimentation Project (091059314).

\section{References}

1. (a) Sudik, A.-C.; Côté, A.-P.; Wong-Foy, A.-G.; O'Keeffe, M.; Yaghi, O. M. Angew. Chem., Int. Ed. 2006, 45, 2528. (b) Hong,
M.-C. Cryst. Growth Des. 2007, 7, 10. (c) Robson, R. Dalton Trans. 2008, 5113. (d) Shi, X. -J.; Wang, X.; Li, L.-K.; Hou, H.-W.; Fan, Y.-T. Cryst. Growth Des. 2010, 10, 2490.

2. (a) Poulsen, R. D.; Bentien, A.; Chevalier, M.; Iversen, B. B. J. Am. Chem. Soc. 2005, 127, 9156. (b) Luo, F.; Hu, D.-X.; Xue, L.; Che, Y.-X.; Zheng, J.-M. Cryst. Growth Des. 2007, 7, 851. (c) Xiang, S.-C.; Wu, X.-T.; Zhang, J.-J.; Fu, R.-B.; Hu, S.-M.; Zhang, X.-D. J. Am. Chem. Soc. 2005, 127, 16352.

3. (a) Yaghi, O. M.; Li, H.-L. J. Am. Chem. Soc. 1996, 118, 295. (b) Min, K.-S.; Suh, M.- P. J. Am. Chem. Soc. 2000, 122, 6834.

4. (a) Hu, S.; Zhang, J.-P.; Li, H.-X.; Tong, M.-L.; Chen, X.-M.; Kitagawa, S. Cryst. Growth Des. 2007, 7, 2286. (b) Kitagawa, S.; Kitaura, R.; Noro, S. Angew. Chem.,Int. Ed. 2004, 43, 2334. (c) Mckinlay, R. M.; Thallapally, P. K.; Atwood, J. L. Chem. Commun. 2006, 2956.

5. (a) Wu, C.-D.; Hu, A.; Zhang, L.; Lin, W.-B. J. Am. Chem. Soc. 2005, 127, 8940. (b) Ohmori, O.; Fujita, M. Chem. Commun. 2004, 1586. (c) Fujita, M.; Kwon, Y. J.;Washizu, S.; Ogura, K. J. Am. Chem. Soc. 1994, 116, 1151. (d) Seo, J.-S.; Whang, D.; Lee, H.; Jun, S.-I.; Oh, J.; Jeon, Y.-J.; Kim, K. Nature 2000, 404, 982.

6. Myers, L. K.; Langhoff, C.; Thompson, M. E. J. Am. Chem. Soc. 1992, 114,7560 .

7. (a) Liu, X.; Huang, K.-L. Inorg. Chem. 2009, 48, 8653. (b) Liu, X.-Q.; Liu, Y.-Y.; Hao, Y.-J.; Yang, X.-J.; Wu, B. Inorg. Chem. Commun. 2010, 13, 511.

8. (a) Wang, B.; Côté, A. P.; Furukawa, H.; O’Keeffe, M.; Yaghi, O. M. Nature 2008, 453, 207. (b) Banerjee, R.; Phan, A.; Wang, B.; Knobler, C.; Furukawa, H.; O'Keeffe, M.; Yaghi, O. M. Science 2008, 319, 939. (c) Hayashi, H.; Côté, A. P.; Furukawa, H.; O’Keeffe, M.; Yaghi, O. M. Nat. Mater. 2007, 6, 501.

9. (a) Hulvey, Z.; Ayala, E.; Furman, J. D.; Forster, P. M.; Cheetham, A. K. Cryst. Growth Des. 2009, 9, 4759. (b) Wen, L.-L.; Li, Y.-Z.; Lu, Z.-D.; Lin, J.-G.; Duan, C.-Y.; Meng, Q.-J. Cryst. Growth Des. 2006, 6, 530 .

10. Mo, H.-J.; Zhong, Y.-R.; Cao, M.-L.; Ou, Y.-C.; Ye, B.-H. Cryst. Growth Des. 2009, 9, 488.

11. (a) Zheng, S.-R.; Yang, Q.-Y.; Yang, R.; Pan, M.; Cao, R.; Su, C.-Y. Cryst. Growth Des. 2009, 9, 2341. (b) Cunha-Silva, L.; Lima, S.; Ananias, D.; Silva, P.; Mafra, L.; Carlos, L. D.; Pillinger, M.; Valente, A. A.; Almeida Paz, F. A.; Rocha, J. J. Mater. Chem. 2009, 17, 2618.

12. (a) Banerjee, R.; Furukawa, H.; Britt, D.; Knobler, C.; O'Keeffe, M.; Yaghi, O. M. J. Am. Chem. Soc. 2009, 131, 3875. (b) Sirjoosingh, A.; Alavi, S.; Woo, T. K. J. Phys. Chem. C. 2010, 114, 2171. (c) Baburin, I. A.; Leoni, S.; Seifert, G. J. Phys. Chem. B 2008, 112, 9437. (d) Phan, A.; Doonan, C. J.; Uribe-Romo, F. J.; Knobler, C. B.; O'keeffe, M.; Yaghi, O. M. Acc. Chem. Res. 2010, 43, 58.

13. (a) Ye, B.-H.; Ding, B.-B.; Weng, Y.-Q.; Chen, X.-M. Cryst. Growth Des. 2005, 5, 801. (b) Ding, B.-B.; Weng, Y.-Q.; Mao, Z.-W.; Lam, C.-K.; Chen, X.-M.; Ye, B.-H. Inorg. Chem. 2005, 44, 8836.

14. (a) Moon, D.; Lah, M. S. Inorg. Chem. 2002, 41, 4708. (b) Choi, H. J.; Suh, M. P. Inorg. Chem. 1999, 38, 6309. (c) Cui, R.-H.; Xu, Y.-H.; Jiang, Z.-H. Inorg. Chem. Commun. 2009, 12, 933. (d) Li, X.-P.; Zhang, J.-Y.; Pan, M.; Zheng, S.-R.; Liu, Y.; Su, C.-Y. Inorg. Chem. 2007, 46, 4617. (e) Jang, J.-J.; Li, L.; Yang, T.; Kuang, D.-B.; Wang, W.; Su, C.-Y. Chem. Commun. 2009, 238.

15. Li, X.-P.; Pan, M.; Zheng, S.-R.; Liu, Y.-R.; He, Q.-T.; Kang, B.-S.; Su, C.-Y. Cryst. Growth Des. 2007, 7, 2481.

16. (a) Li, H.; Eddaoudi, M.; O'Keeffe, M.; Yaghi, O. M. Nature 1999, 402, 276. (b) Chui, S. S. Y.; Lo, S. M. F.; Charmant, J. P. H.; Orpen, A. G.; William, I. D. Science 1999, 1148, 283. (c) Kim, J.; Chen, B.; Reineke, T. M.; Li, H.; Eddaoudi, M.; Moler, D. B.; ÓKeeffe, M.; Yaghi, O. M. J. Am. Chem. Soc. 2001, 123, 8239. (d) Wang, Z.-Q.; Kravtsov, V. C.; Zaworotko, M. J. Angew. Chem., Int. Ed. 2005, 44, 2877. (e) Barthelet, K.; Marrot, J.; Riou, D.; Férey, G. Angew. Chem., Int. Ed. 2002, 41, 281.

17. (a) Zheng, Y.-Q.; Lin, J.-L. Z. Kristallogr. New Cryst. Struct. 2000, 157, 215. (b) Suresh, E.; Bhadbhade, M. M.; Venkatasubramanian, 
K. Polyhedron 1999, 657, 18.

18. (a) Zheng, Y.-Q.; Lin, J.-L.; Pan, A.-Y. Z. Anorg. Allg. Chem. 2000, 1718, 626. (b) Fleck, M.; Tillmanns, E.; Bohaty, L. Z. Kristallogr. New Cryst. Struct. 2000, 619, 215.

19. Michaelides, A.; Kiritsis, V.; Skoulika, S.; Aubry, A. Angew. Chem. Int. Ed. 1993, 32, 1495.

20. (a) Prajapati, R.; Mishra,L.; Kimura, K.; Raghavaiah, P. Polyhedron 2009, 28, 600. (b) Zhang, L.-Y.; Liu, G.-F.; Zheng,S.-L.; Ye, B.-H.; Zhang, X.-M.; Chen, X.-M. Eur. J. Inorg. Chem. 2003, 2965.

21. (a) Lucinda, M. D.; Eleni,V.; Eduardo, G. V.; Peter, L.; Alexander, J. B.; Claire, W.; Martyn, P. Green Chem. 2003, 5, 187. (b). Wang, Z.-Y.; Wang, L.-G. Chinese J. Struct. Chem. 2005, 24, 35.

22. Sheldrick, G. M.: A short history of SHELX. Acta Crystallogr. 2008, $A 64,112$.

23. Addison, A. W.; Rao, T. N. J. Chem. Soc. Dalton Trans. 1984, 1349.

24. Afreen, F.; Mathur, P.; Rheingold, A. Inorg. Chim. Acta 2005 , 358,1125 .

25. Kong, L-.L.; Gao, S.; Huo, L.-H.; Ng, S.W. Acta Cryst. 2003, E59, $\mathrm{m} 3153$.

26. (a) Sun, J.-Y.; Tong, X.-D.; Xu, H.-Z. Inorg. Chem. Commun. 2010 13, 645. (b) Piguet, C.; Williams, A. F.; Bernardinell, G.; Moret,
E.; Bünzli, J. C. G. Helv. Chim. Acta 1992, 75, 1697.

27. Liu, S.-G.; Zuo, J.-L.; Li, Y.-Z.; You, X.-Z. J. Mol. Struct. 2004, $705,153$.

28. Meng, F.-Y.; Zhou, Y.-L.; Zou, H.-H.; Zeng, M.-H.; Liang, H. J. Mol. Struct. 2009, 920, 238.

29. (a) Lin, Y.-W.; Tong, Y.-P. Inorg. Chem. Commun. 2009, 12, 208. (b) Chen, C.-L.; Zhang, Q.; Yao, J.-H.; Zhang, J.-Y.; Kang B.-S.; Su, C.-Y. Inorg. Chim. Acta. 2008, 361, 2934. (c) Huang, L.; Zhong, A.-G.; Chen, D.-B.; Liang, H.-D. J. Mol. Struct. 2009, 922, 135. (d) Xiao, B.; Hou H.-W.; Fan,Y.-T.; Tang, M.-S. Inorg. Chem. Commun. 2007, 10, 376.

30. (a) Guo, C.-Y.; Wang, Y.-Y.; Xu, K.-Z.; Zhu, H.-L.; Liu, P.; Shi, Q. Z.; Peng. S. M. Polyhedron 2008, 27, 3529. (b) Che, G.-B.; Liu, C.-B.; Liu, B.; Wang, Q.-W.; Xu, Z.-L. Cryst Eng Comm. 2008, 10, 184. (c) Zou, J.-P.; Peng, Q.; Wen, Z.-H.; Zeng, G.-S.; Xing, Q.-J.; Guo, G.-C. Cryst. Growth Des. 2010, 10, 2613.

31. (a) Zhang, J.-P.; Lin, Y.-Y.; Huang, X.-C.; Chen, X.-M. J. Am. Chem. Soc. 2005, 127, 5495. (b) Zou, J.-P.; Wen, Z. H.; Peng, Q.; Zeng, G.-S.; Xing, Q.-J.; Chen, M.-H. J. Coord. Chem. 2009, 62, 3324.

32. Wei, K.-J.; Ni, J.; Xie, Y.-S.; Liu, Q.-L. Inorg. Chem. Commun. 2007, 10, 279 . 